Int. J. Dev. Biol. 60: 271-276 (2016)

doi: $10.1387 / \mathrm{ijdb} .130188 \mathrm{ds}$

\title{
Chaperone-mediated chromatin assembly and transcriptional regulation in Xenopus laevis
}

\author{
TAKASHI ONIKUBO* and DAVID SHECHTER* \\ Department of Biochemistry. Albert Einstein College of Medicine, Bronx, NY, USA
}

\begin{abstract}
Chromatin is the complex of DNA and histone proteins that is the physiological form of the eukaryotic genome. Chromatin is generally repressive for transcription, especially so during early metazoan development when maternal factors are explicitly in control of new zygotic gene expression. In the important model organism Xenopus laevis, maturing oocytes are transcriptionally active with reduced rates of chromatin assembly, while laid eggs and fertilized embryos have robust rates of chromatin assembly and are transcriptionally repressed. As the DNA-to-cytoplasmic ratio decreases approaching the mid-blastula transition (MBT) and the onset of zygotic genome activation (ZGA), the chromatin assembly process changes with the concomitant reduction in maternal chromatin components. Chromatin assembly is mediated in part by histone chaperones that store maternal histones and release them into new zygotic chromatin. Here, we review literature on chromatin and transcription in frog embryos and cell-free extracts and highlight key insights demonstrating the roles of maternal and zygotic histone deposition and their relationship with transcriptional regulation. We explore the central historical and recent literature on the use of Xenopus embryos and the key contributions provided by experiments in cell-free oocyte and egg extracts for the interplay between histone chaperones, chromatin assembly, and transcriptional regulation. Ongoing and future studies in Xenopus cell free extracts will likely contribute essential new insights into the interplay between chromatin assembly and transcriptional regulation.
\end{abstract}

KEY WORDS: transcription, histone chaperone, H2A-H2B, H3-H4

Chromatin and transcription have long been known to be interrelated, especially during the remarkable regulatory transitions that occur during early metazoan embryogenesis. The eukaryotic genome in vivo is composed of DNA complexed with histone proteins in an assembly called chromatin (Shechter and Allis, 2007). Histone deposition and chromatin assembly pathways have a long history of discovery in Xenopus cell-free extracts, providing key insights with broad application to eukaryotic biology and human health and disease. Here, we highlight the continuing relevance of the unique attributes of Xenopus cell-free extracts for crucial insights into the biological pathways performing chromatin assembly and transcriptional regulation. We also describe important discoveries about the function and mechanism of histone chaperones made in Xenopus.

\section{Animal development, chromatin and transcription}

Animal development is initially programmed by maternal RNAs and proteins deposited in the egg. Zygotic control supersedes the maternal program during the maternal-to-zygotic transition (MZT) when zygotic genome activation (ZGA) occurs (O'Farrell et al., 2004, Schier, 2007, Tadros and Lipshitz, 2009). This transition is frequently concomitant with the substantial cell-cycle and morphological changes at the mid-blastula transition (MBT). The MZT occurs in all metazoans, but not always at the same developmental time as the MBT. Intriguingly, the timing of this transcriptional transition is highly species-dependent (O'Farrell et al., 2004). In zebrafish the transition occurs at the $10^{\text {th }}$ cell cycle, in Xenopus laevis the transition occurs at roughly the $12^{\text {th }}$ cell cycle, in fruit flies it occurs at the 13th cell cycle, while in mammals it occurs in the first or second cell cycle (Schier, 2007, Tadros and Lipshitz, 2009). This observation is consistent with the hypothesis that the

Abbreviations used in this paper: MBT, mid-blastula transition; ZTA, zygotic genome activation.

\footnotetext{
*Address correspondence to: David Shechter. Department of Biochemistry. Albert Einstein College of Medicine, 1300 Morris Park Avenue, Bronx, NY 10461, USA. E-mail: david.shechter@einstein.yu.edu - www.shechterlab.org
}

\#Present address: The Rockefeller University, New York, NY 10065, USA.

Accepted: 13 June 2016.

ISSN: Online 1696-3547, Print 0214-6282 
dramatically distinct body plans and developmental programs across the metazoan kingdom may be in part specified by differences in timing of zygotic gene expression (Fernandez-Tresguerres et al., 2010, O'Farrell et al., 2004).

\section{Xenopus frogs as a model system for chromatin and transcriptional regulation}

Frogs of the genus Xenopusare commonly used vertebrate model systems for studying development, cell cycle, cancer, chromatin, and many other biological phenomena. Xenopus laevis are evolutionarily close to mammals in comparison to other model organisms like yeasts, $C$. elegans, or Drosophila, with substantial homology and complementation among proteins, making them a compelling model for biology as well as human health and disease. Xenopus frogs have been used as a laboratory experimental system for a long time and have a history of producing crucial observations in many fields of biology, including being the first vertebrate successfully used for somatic-cell nuclear transfer (Gurdon, 1962). Frogs lay thousands of large eggs, from which cell free extract can be readily prepared that is capable of recapitulating most molecular phenomena in a test tube. The extract can be fractionated, its cell cycle state altered, and drugs and proteins can be added and removed to modulate activities (Costanzo and Gautier, 2004, Costanzo et al., 2004, Hutchison et al., 1988, Tutter and Walter, 2006). Xenopus cell-free egg extracts recapitulate most biological phenomena in a biochemically dissectible form.

The Xenopus model system is an unrivaled system for testing hypotheses as biochemical and biological studies can be conducted in parallel. Xenopus biology is exceedingly conserved with mammals and many seminal discoveries have been made with frogs with substantial implications for human biology. Furthermore, the bias of cleavage-stage eggs and embryos towards rapid replication is a major benefit for chromatin and transcriptional regulation studies, as these amplified conditions serve to enhance the phenotypes. Additionally, somatic cell nuclear transfer to reprogram adult frog or mammalian nuclei in Xenopus oocytes, eggs, and cell-free extracts have promoted essential understanding of the roles of transcription factors and chromatin function in global transcriptional reprogramming (Gurdon, 1962, Hansis et al., 2004, Simeoni et al., 2011). Our laboratory has made extensive use of these cell free extracts for probing chromatin assembly, histone modifications, and transcriptional regulation (Banaszynski et al., 2010, Nicklay et al., 2009, Onikubo et al., 2015, Shechter et al., 2009a, Shech- ter et al., 2009b, Wang et al., 2014, Wang and Shechter, 2016, Wilczek et al., 2011).

\section{Xenopus development and transcriptional regulation}

Post-fertilization embryonic Xenopus cells are transcriptionally silenced and rapidly alternate between S-phase and M-phase (Laskey, 1985). This transcriptional quiescence and rapid cycling allows the embryo to undergo an accelerated and synchronized cell division and represents an epigenetic phenomenon of mitotic inheritance of transcriptional repression. These processes continue until the MBT and concomitant ZGA at developmental stages 8/9 (Fig. 1). Prior to ZGA, maternal stores are the only cellular source of proteins and mRNAs. This suggests that the quantity of maternally stored material, including the histones that are the major protein component of chromatin, is large enough to support the approximately 4,000 cells in stage 9 embryos. Indeed, substantial evidence shows that histone proteins are stored in vast excess in eggs compared to somatic cells (Almouzni and Wolffe, 1993a, Woodland, 1979, Woodland and Adamson, 1977). However, no available evidence indicates whether stored histone proteins are in adequate abundance for complete chromatin assembly through ZGA or if new histone translation from stored mRNAs is necessary for development. New mass spectrometry technologies and highly specific antibodies may allow precise determination of the mass of histones present.

\section{Chromatin in the frog early embryo}

The fundamental repeating unit of chromatin is the nucleosome, in which DNA is wrapped around an octamer of the four core histones, H2A, H2B, H3, and H4 (Luger et al., 1997, Van Holde, 1989). Linker histones and other protein components further condense and arrange chromatin (Ausio, 2006, Woodcock et al., 2006). Transcription assays in vitro have shown that nucleosomes efficiently block transcription and that transcriptional activation requires structural alteration of nucleosomes (Venkatesh and Workman, 2015). Post-translational modifications of histones, along with deposition of variant and linker histones, form a "histone code" regulating the usage of the underlying DNA (Strahl and Allis, 2000). Since at least some of these modifications can be retained across cell divisions, these histone modifications may serve as a memory for transcriptional states, forming the basis of epigenetic gene regulations and establishment of cell type-specific transcrip-
Fig. 1. Cartoon of early development and the timing of transcription and chromatin assembly. During Xenopus laevis early development (morphological stages 1-17 shown), maternally deposited mRNA transcripts are consumed (purple) while new zygotic mRNA transcripts (b/ue) are first synthesized during the developmental transition of the MBT/ ZGA (Mid-blastula transition / zygotic genome activation). Histone chaperones store maternal histones and deposit them during the exponential chromatin assembly (gray) of new zygotic DNA prior to the MBT.

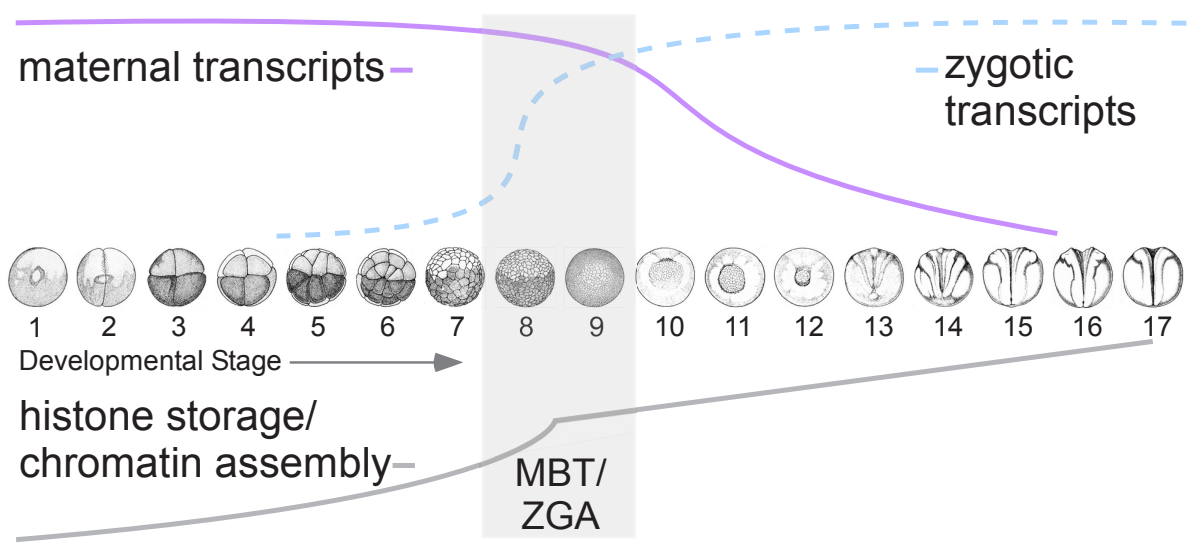


tome (Ramachandran and Henikoff, 2015).

We previously showed that dynamic changes in deposition of histone variants and alterations of post-translational modification patterns occur throughout the life of a multicellular organism and vary in each cell type (Nicklay et al., 2009, Shechter et al., 2009a, Shechter et al., 2009b, Wang et al., 2014). There are likely several proximate regulatory regimes overseeing this significant developmental switch. We favor the hypothesis that specific repressive components of chromatin suppress assembly and activation of RNA Polymerase II transcriptional complexes (Almouzni et al., 1990b, Almouzni et al., 1991, Dimitrov et al., 1993, Hair et al., 1998, Prioleau et al., 1995, Prioleau et al., 1994, Wolffe et al., 1993) as our experimental work in this issue also supports this model in which chromatin assembly suppresses transcription in egg extract while nucleation of transcription by pre-binding of TBP stimulates transcription (Wang and Shechter, 2016). In this hypothesis, as the nuclear-to-cytoplasmic ratio decreases approaching the MBT and the chromatin assembly process changes with the diminution of maternal chromatin components, transcription may then commence, subject to normal signaling, transcription factors, and histone modification pathways (Fig. 1). Other hypotheses may also be valid: for instance, exogenous TBP protein can induce transcription on a reporter plasmid in cell-free egg extract (Almouzni and Wolffe, 1995, Hair et al., 1998, Prioleau et al., 1994), suggesting that the recruitment of the polymerase machinery may be compromised in the early embryo.

Chromatin assembly, the deposition of histones onto chromatin to form nucleosomes, is highly efficient in Xenopus eggs, early embryos, and in egg extract. Any DNA incubated in egg extract is rapidly assembled into a histone containing complex (Almouzni et al., 1990a, Laskey et al., 1977). In embryos, fertilization and during subsequent early embryo cell cycles prior to the MBT, histone deposition and chromatin assembly of newly replicated DNA is robust and rapid (Amodeo et al., 2015, Collart et al., 2013). In Xenopus, embryos reach the $12^{\text {th }}$ cell cycle in five hours post fertilization, and the chromatin formed during these stages are enriched for histone variant, modifications, and linker histones specific to the embryo. In particular, we previously showed that $X$. laevis embryos have elevated incorporation of histone H2A.X.3 (previously called H2A.X-F), a variant frequently associated with the cell cycle checkpoints, and a unique maternal linker histone called H1.M (previously B4) (Shechter et al., 2009a, Wang et al., 2014). H1.M is essential for mesodermal competence during frog development (Steinbach et al., 1997). An open question remains as to the specific role of these histone variants and how they are deposited into chromatin, although a reasonable hypothesis for H2A.X.3 is that it suppresses aberrant checkpoint activation during the rapid early cell cycles (Shechter et al., 2009a). Maternal linker histones $\mathrm{H} 1$. Mare differentially deposited in oocyte and egg extracts and may correlate with gene expression and repression (Dimitrov et al., 1994, Nightingale et al., 1996, Sera and Wolffe, 1998).

Associated with ZGA is rapid incorporation of the zygotically expressed somatic histones (Wang et al., 2014). We favor the hypothesis that the rapid rate of histone deposition and the presence of maternal histones and histone post-translational modifications is, in part, responsible for the suppression of zygotic transcription (Wang et al., 2014, Wang and Shechter, 2016). This is supported by the evidence that the nuclear-to-cytoplasmic ratio and the depletion of maternal histones are important for this regulation
(Amodeo et al., 2015).

These processes are directly dissectible in oocytes and eggs, which are transcriptionally active and repressed, respectively. Previous analyses of chromatin assembly, nuclear assembly, DNA replication and transcription in oocyte and egg extracts were performed over twenty years ago and revealed clear differences. Oocyte extract was found not to be able to replicate DNA or assemble nuclei on sperm chromatin (Cox and Leno, 1990). Wolffe, Almouzni and colleagues showed essential activities in cell free extracts for assembling chromatin through many seminal papers (Almouzni et al., 1990a, Almouzni et al., 1990b, Almouzni et al., 1991, Almouzni and Wolffe, 1993a, Almouzni and Wolffe, 1993b). These activities are also essential for reprogramming of somatic nuclei in cell-free egg extract (Miyamoto et al., 2007), although further chromatin rearrangement through mitosis appears to be essential (Ganier et al., 2011, Lemaitre et al., 2005).

In Xenopus sperm chromatin, protamines (Sperm Specific Basic Proteins 1-6) are assembled in place of core histones for extreme compaction, although much $\mathrm{H} 3-\mathrm{H} 4$ remains in the mature spermatids (Frehlick et al., 2007, Katagiri and Ohsumi, 1994, Shechter et al., 2009b). After fertilization, or in pronuclear assembled on sperm chromatin in egg extract, the highly compacted sperm chromatin is decondensed with concomitant deposition of maternally-stored, chaperone-complexed H2A-H2B (Philpott etal., 1991), establishing the paternal component of the new embryonic chromatin.

\section{Histones and histone chaperones: key function and insight from Xenopus}

Nucleosome assembly in a cell is a highly regulated process involving many factors, including histone chaperones, which bind histones and escort them onto DNA, and ATP-dependent chromatin remodelers, which form bona fide nucleosomes (Burgess and Zhang, 2013). A recent thorough review of histone chaperones provides an overview (Gurard-Levin et al., 2014). Histone H3-H4 is passed down a collection of molecular and histone chaperones, from Hsp70, Hsp90, NASP (formerly called N1 in Xenopus), Asf1, and to HIRA or CAF1 for deposition (Campos et al., 2010, Mattiroli et al., 2015). CAF-1, the H3-H4 chaperone used during replication, is critical for tight coupling of chromatin assembly to DNA replication in Xenopus (Quivy et al., 2001). Histone H2A-H2B are chaperoned by Nucleoplasmin family members (Npm1, Npm2, and Npm3), Nap1, and FACT (Gurard-Levin et al., 2014). Much of the elucidation of these pathways was accomplished in Xenopus cell-free egg extracts, with identification of Nucleoplasmin (Npm2) in the 1970s (Earnshaw et al., 1980, Laskey et al., 1978), the first protein to be called a chaperone, and the identification of N1/N2 (likely proteins from alloalleles that we now denote as $N 1 a$ and $N 1 b$, homologous to mammalian NASP) in the 1980s (Kleinschmidt et al., 1985).

Npm2 was originally discovered in egg extract as a protein that neutralized the positive charges of histones and assembled nucleosomes on a plasmid DNA under physiological salt concentrations in vitro (Laskey et al., 1978). This charge attenuation by Npm was identified as the critical factor that inhibited histone aggregation and promoted the proper histone deposition onto DNA and led to the concept and the term "molecular chaperones" to describe Npm and its function (Earnshaw et al., 1980). We and others have shown that Npm contains many post-translational modifications, including phosphorylation, glutamylation, and arginine methylation, and these 
modifications were found to regulate the chaperoning functions of Npm. In particular, phosphorylation on the short and intrinsically disordered N-terminal tail was found to promote sequestration of histones in vitro and suggested that the histone storage function of $\mathrm{Npm}$ is also activated through phosphorylation in this region (Onikubo et al., 2015). Further work on Npm histone storage and the identification of the interaction sites necessary for histone sequestration will shed light on the molecular mechanism of histone binding and release. Such knowledge will also provide significant insights into the molecular mechanisms of how the switch between histone assembly and disassembly is regulated with multi-functional somatic histone chaperones such as Nap1 and Asf1. It is also of interest that Npm presence continues long after ZGA, but its hyperphosphorylation, a characteristic feature of Npm during the early stages of development, is lost, while retaining other modifications such as glutamylation and arginine methylation. This observation suggests that Npm may have additional roles, such as linker histone exchange. Ongoing study using the Xenopus model will continue to be a significant tool for studying histone chaperone functions with direct application to other eukaryotes and human biology.

The complexity of histone chaperone networks is seen in the fact that many of these proteins are involved in multiple and often opposite functions. Nucleoplasmin, when heavily phosphorylated and otherwise modified in the egg, decondenses sperm chromatin (Philpott et al., 1991) yet binds and sequesters core histones (Onikubo et al., 2015). NASP participates in H3-H4 dimer assembly in the cytoplasm (Campos et al., 2010), stores H3-H4 in the egg (Finn et al., 2012), and also directly transfers linker histones into the nucleus (Finn et al., 2008). Asf1 is a histone chaperone responsible for H3-H4 import into nucleus, but Asf1 has also been implicated in the disassembly of nucleosomes during DNA replication and during transcription (English et al., 2006). Interestingly, Asf1 is dispensable for de novo histone deposition in Xenopus egg extracts (Ray-Gallet et al., 2007). The reason for this is not clear, but is perhaps due to its function in replicational stress histone buffering (Groth et al., 2005). Nap1 is a histone chaperone responsible for histone $\mathrm{H} 2 \mathrm{~A}-\mathrm{H} 2 \mathrm{~B}$ transport into the nucleus and is implicated in $\mathrm{H} 2 \mathrm{~A}-\mathrm{H} 2 \mathrm{~B}$ deposition during DNA replication, while it also chaperones linker histones and is implicated in nucleosome disassembly during transcription. Importantly, post-translational glutamylation of Nap1 significantly altered linker histone dynamics on mitotic chromosomes in Xenopus egg extract (Miller and Heald, 2015). FACT is an $\mathrm{H} 2 \mathrm{~A}-\mathrm{H} 2 \mathrm{~B}$ and $\mathrm{H} 3-\mathrm{H} 4$ chaperone involved in transcriptional regulation, but intriguingly was recently shown to be responsible for the assembly of H2A.X.3 into Xenopus mitotic chromosomes in a reconstituted system, suggesting that many disparate roles exist for chaperones (Shintomi et al., 2015). HIRA, a specialized chaperone for the transcriptionally-activating histone variant H3.3, is present in Xenopus oocytes and eggs and is essential for replication independent nucleosomal assembly (Ray-Gallet et al., 2002), required for proper gastrulation and $\mathrm{H} 3.3$ deposition (Szenker et al., 2012), and transcriptional reprogramming in nuclear transfer to oocytes (Jullien et al., 2012).

The multiple functions of each histone chaperone and redundant functions among histone chaperones have made the functional analyses of histone chaperones difficult using direct genetic approaches in cells. This is evidenced by a surprising observation that no histone chaperones have been shown to be essential in mammalian cells or in yeast despite their involvement in essential biological functions, such as DNA replication and transcription. Therefore, the molecular mechanisms of the functional switch between nucleosome assembly and disassembly during DNA replication and transcription currently remain unknown and provide unique opportunity for continued investigation in Xenopus cell-free extracts in which they can be biochemically probed - by immunodepletion/ add-back experiments - and in the absence of ongoing transcription.

\section{Transcription and reprogramming in the early embryo}

The mechanism by which the pre-MBT global transcriptional block occurs is a long-standing and unanswered question. Cell free extracts have been invaluable for deciphering this regulation of transcription during early development. Xenopus oocyte extracts are capable of transcribing any reporter plasmid with a strong promoter (i.e. CMV, adenovirus), while laid egg extracts are only capable of transcribing the reporter plasmid if it has been pre-incubated with the TATA-binding protein TBP, a component of the TFIID basal transcriptional apparatus (Dimitrov and Wolffe, 1995, Toyoda and Wolffe, 1992). This phenomenon was hypothesized to occur due to a race between chromatin assembly and transcriptional complex assembly (Almouzni et al., 1990b), and may explain the global transcriptional quiescence in the egg. Our new experiments directly demonstrate these phenomena (Wang and Shechter, 2016).

Egg extracts have also been used to test mechanisms of reprogramming the transcriptional state, and perhaps by reverting to the global transcriptional quiescence found in the egg, insights into pluripotency can be further elaborated (Hansis et al., 2004, Jullien et al., 2010, Lemaitre et al., 2005, Simeoni et al., 2011). An ATP-dependent reaction catalyzed by the nucleosomal remodeling component ISWI was responsible for active remodeling of somatic nuclei in the egg. This activity was assayed in part by the loss of TBP protein from somatic nuclei incubated in egg extract, and also by the acquisition of a number of embryonic-specific components, including Npm, TFIIF $\alpha$, and histone B4 (Kikyo et al., 2000). Consistently, the ATPase Brg1 was critical for mammalian nuclear reprogramming in cell-free egg extract (Hansis et al., 2004). We have identified other egg protein components that are acquired by remodeled sperm and somatic chromatin: proteins involved in nuclear pore and nucleolar assembly as well as the embryonic linker histone B4 (Fig. 1F in ref. Shechter et al., 2009b). Significantly, acquisition of B4 is an early step in somatic cell reprogramming upon injection into Xenopus oocytes (Jullien et al., 2010). These observations are consistent with an active remodeling process in the egg. Since maternal chaperones store the histones that comprise potential key components of the transcriptional competence of egg-reprogrammed nuclei, evidence demonstrating that exogenous Nucleoplasmin enhances the efficiency of reprogramming (Betthauser et al., 2006, Huynh et al., 2016) suggests that future studies on maternal histone chaperones will provide new research directions for stem cell research.

\section{Conclusions}

The relationship between chromatin, chromatin assembly, and transcriptional regulation is an essential component of the development of multicellular organisms. Xenopus laevis has been a crucial model organism and tool for the study of these events and still holds tremendous potential for further dissection of these processes. In particular, the role of specific aspects of chromatin 
assembly and histone PTMs in the relationship with the onset of zygotic transcription is unclear. Since histone chaperones are a large class of proteins responsible for key aspects of chromatin metabolism, they lie at the fulcrum of important current areas of research. Future studies, especially in Xenopus cell-free extracts, hold great promise in further elucidation of mechanisms of these critical biological pathways.

\section{Acknowledgments}

This work was supported by startup funds from the Albert Einstein College of Medicine, The American Cancer Society - Robbie Sue Mudd Kidney Cancer Research Scholar Grant (124891-RSG-13-396-01-DMC) and NIH R01GM108646.

\section{References}

ALMOUZNI, G., CLARK, D., MÉCHALI, M. and WOLFFE, A. (1990a). Chromatin assembly on replicating DNA in vitro. Nucleic Acids Res 18: 5767-5774.

ALMOUZNI, G., MÉCHALI, M. and WOLFFE, A. (1990b). Competition between transcription complex assembly and chromatin assembly on replicating DNA. EMBO J 9: 573-582.

ALMOUZNI, G., MÉCHALI, M. and WOLFFE, A. (1991). Transcription complex disruption caused by a transition in chromatin structure. Mol Cell Biol 11: 655-665.

ALMOUZNI, G. and WOLFFE, A. (1993a). Nuclear assembly, structure, and function: the use of Xenopus in vitro systems. Exp Cell Res 205: 1-15.

ALMOUZNI, G. and WOLFFE, A. (1993b). Replication-coupled chromatin assembly is required for the repression of basal transcription in vivo. Genes Dev7:2033-2047.

ALMOUZNI, G. and WOLFFE, A. (1995). Constraints on transcriptional activator function contribute to transcriptional quiescence during early Xenopus embryogenesis. EMBO J 14: 1752-1765.

AMODEO, A.A., JUKAM, D., STRAIGHT, A.F. and SKOTHEIM, J.M. (2015). Histone titration against the genome sets the DNA-to-cytoplasm threshold for the Xenopus midblastula transition. Proc Natl Acad Sci USA 112: E1086-E1095.

AUSIO, J. (2006). Histone variants--the structure behind the function. Brief Funct Genomic Proteomic 5: 228-243.

BANASZYNSKI, L.A., ALLIS, C.D. and SHECHTER, D. (2010). Analysis of histones and chromatin in Xenopus laevis egg and oocyte extracts. Methods 51: 3-10.

BETTHAUSER, J.M., PFISTER-GENSKOW, M., XU, H., GOLUEKE, P.J., LACSON, J.C., KOPPANG, R.W., MYERS, C., LIU, B., HOESCHELE, I., EILERTSEN, K.J. et al., (2006). Nucleoplasmin facilitates reprogramming and in vivo development of bovine nuclear transfer embryos. Mol Reprod Dev 73: 977-986.

BURGESS, R.J. and ZHANG, Z. (2013). Histone chaperones in nucleosome assembly and human disease. Nat Struct Mol Biol 20: 14-22.

CAMPOS, E.I., FILLINGHAM, J., LI, G., ZHENG, H., VOIGT, P., KUO, W.H., SEEPANY, H., GAO, Z., DAY, L.A., GREENBLATT, J.F. etal., (2010). The program for processing newly synthesized histones H3.1 and H4. Nat Struct Mol Biol 17: 1343-1351.

COLLART, C., ALLEN, G.E., BRADSHAW, C.R., SMITH, J.C. and ZEGERMAN, P. (2013). Titration of Four Replication Factors Is Essential for the Xenopus laevis Midblastula Transition. Science 341(6148), pp. 893-896. (DOI: 10.1126/ science.1241530).

COSTANZO, V. and GAUTIER, J. (2004). Xenopus cell-free extracts to study DNA damage checkpoints. Methods Mol Biol 241: 255-267.

COSTANZO, V., ROBERTSON, K. and GAUTIER, J. (2004). Xenopus cell-free extracts to study the DNA damage response. Methods Mol Biol 280: 213-227.

COX, L.S. and LENO, G.H. (1990). Extracts from eggs and oocytes of Xenopus laevis differ in their capacities for nuclear assembly and DNA replication. J. Cell Sci. 97: 177-184.

DIMITROV, S., ALMOUZNI, G., DASSO, M. and WOLFFE, A. (1993). Chromatin transitions during early Xenopus embryogenesis: changes in histone $\mathrm{H} 4$ acetylation and in linker histone type. Dev Biol 160: 214-227.

DIMITROV, S., DASSO, M. and WOLFFE, A. (1994). Remodeling sperm chromatin in Xenopus laevis egg extracts: the role of core histone phosphorylation and linker histone B4 in chromatin assembly. J Cell Biol 126: 591-601.
DIMITROV, S. and WOLFFE,A. (1995). Chromatin and nuclear assembly: experimental approaches towards the reconstitution of transcriptionally active and silent states. Biochim Biophys Acta 1260: 1-13.

EARNSHAW, W., HONDA, B., LASKEY, R. and THOMAS, J. (1980). Assembly of nucleosomes: the reaction involving $X$. laevis nucleoplasmin. Cell 21: 373-383.

ENGLISH, C.M., ADKINS, M.W., CARSON, J.J., CHURCHILL, M.E. and TYLER, J.K. (2006). Structural basis for the histone chaperone activity of Asf1. Cell127:495-508.

FERNANDEZ-TRESGUERRES, B., CANON, S., RAYON, T., PERNAUTE, B., CRESPO, M., TORROJA, C. and MANZANARES, M. (2010). Evolution of the mammalian embryonic pluripotency gene regulatory network. Proc Natl Acad Sci USA 107: 19955-19960.

FINN, R.M., BROWNE, K., HODGSON, K.C. and AUSIO, J. (2008). SNASP, a histone $\mathrm{H} 1$-specific eukaryotic chaperone dimer that facilitates chromatin assembly. Biophys J 95: 1314-1325.

FINN, R.M., ELLARD, K., EIRIN-LOPEZ, J.M. and AUSIO, J. (2012). Vertebrate nucleoplasmin and NASP: egg histone storage proteins with multiple chaperone activities. FASEB J 26: 4788-4804.

FREHLICK, L., PRADO, A., CALESTAGNE-MORELLI, A. and AUSIÓ, J. (2007). Characterization of the PL-I-related SP2 protein from Xenopus. Biochemistry 46: $12700-12708$.

GANIER, O., BOCQUET, S., PEIFFER, I., BROCHARD, V., ARNAUD, P., PUY, A. JOUNEAU, A., FEIL, R., RENARD, J.P. and MECHALI, M. (2011). Synergic reprogramming of mammalian cells by combined exposure to mitotic Xenopus egg extracts and transcription factors. Proc Natl Acad Sci USA 108: 17331-17336.

GROTH, A., RAY-GALLET, D., QUIVY, J.P., LUKAS, J., BARTEK, J. and ALMOUZNI, G. (2005). Human Asf1 regulates the flow of $S$ phase histones during replicational stress. Mol Cell 17: 301-311.

GURARD-LEVIN, Z.A., QUIVY, J.-P. and ALMOUZNI, G. (2014). Histone Chaperones: Assisting Histone Traffic and Nucleosome Dynamics. Ann. Rev. Biochem. 83: 487-517.

GURDON, J.B. (1962). The developmental capacity of nuclei taken from intestinal epithelium cells of feeding tadpoles. J Embryol Exp Morphol 10: 622-640.

HAIR, A., PRIOLEAU, M.N., VASSETZKY, Y. and MECHALI, M. (1998). Control of gene expression in Xenopus early development. Dev Genet 22: 122-131.

HANSIS, C., BARRETO, G., MALTRY, N. and NIEHRS, C. (2004). Nuclear reprogramming of human somatic cells by Xenopus egg extract requires BRG1. Curr Biol 14: 1475-1480.

HUTCHISON, C.J., COX, R. and FORD, C.C. (1988). The control of DNA replication in a cell-free extract that recapitulates a basic cell cycle in vitro. Development 103: 553-566.

HUYNH, L.M., SHINAGAWA, T. and ISHII, S. (2016). Two Histone Variants TH2A and TH2B Enhance Human Induced Pluripotent Stem Cell Generation. Stem Cells Dev 25: 251-258.

JULLIEN, J., ASTRAND, C., HALLEY-STOTT, R.P., GARRETT, N. and GURDON, J.B. (2010). Characterization of somatic cell nuclear reprogramming by oocytes in which a linker histone is required for pluripotency gene reactivation. Proc Natl Acad Sci USA 107: 5483-5488.

JULLIEN, J., ASTRAND, C., SZENKER, E., GARRETT, N., ALMOUZNI, G. and GURDON, J.B. (2012). HIRA dependent H3.3 deposition is required for transcriptional reprogramming following nuclear transfer to Xenopus oocytes. Epigen. Chromatin 5: 17.

KATAGIRI, C. and OHSUMI, K. (1994). Remodeling of sperm chromatin induced in egg extracts of amphibians. Int J Dev Biol 38: 209-216.

KIKYO, N., WADE, P.A., GUSCHIN, D., GE, H. and WOLFFE, A.P. (2000). Active remodeling of somatic nuclei in egg cytoplasm by the nucleosomal ATP ase ISWI. Science 289: 2360-2362.

KLEINSCHMIDT, J.A., FORTKAMP, E., KROHNE, G., ZENTGRAF, H. and FRANKE, W.W. (1985). Co-existence of two different types of soluble histone complexes in nuclei of Xenopus laevis oocytes. J Biol Chem 260: 1166-1176.

LASKEY, R. (1985). Chromosome replication in early development of Xenopus laevis. $J$ Embryol Exp Morphol 89 Suppl: 285-296.

LASKEY, R., HONDA, B., MILLS, A. and FINCH, J. (1978). Nucleosomes are assembled by an acidic protein which binds histones and transfers them to DNA. Nature 275: 416-420. 
LASKEY, R., MILLS, A. and MORRIS, N. (1977). Assembly of SV40 chromatin in a cell-free system from Xenopus eggs. Cell 10: 237-243.

LEMAITRE, J., DANIS, E., PASERO, P., VASSETZKY, Y. and MÉCHALI, M. (2005), Mitotic remodeling of the replicon and chromosome structure. Cell 123: 787-801.

LUGER, K., MADER, A.W., RICHMOND, R.K., SARGENT, D.F. and RICHMOND, T.J. (1997). Crystal structure of the nucleosome core particle at 2.8 A resolution. Nature 389: 251-260.

MATTIROLI, F., D'ARCY, S. and LUGER, K. (2015). The right place at the right time: chaperoning core histone variants. EMBO Rep 16: 1454-1466.

MILLER, K.E. and HEALD, R. (2015). Glutamylation of Nap1 modulates histone H1 dynamics and chromosome condensation in Xenopus. J Cell Biol 209: 211-220.

MIYAMOTO, K., FURUSAWA, T., OHNUKI, M., GOEL, S., TOKUNAGA, T., MINAMI, N., YAMADA, M., OHSUMI, K. and IMAI, H. (2007). Reprogramming events of mammalian somatic cells induced by Xenopus laevis egg extracts. Mol Reprod Dev 74: 1268-1277.

NICKLAY, J.J., SHECHTER, D., CHITTA, R.K., GARCIA, B.A., SHABANOWITZ, J., ALLIS, C.D. and HUNT, D.F. (2009). Analysis of histones in Xenopus laevis. II. mass spectrometry reveals an index of cell type-specific modifications on $\mathrm{H} 3$ and H4. J Biol Chem 284: 1075-1085.

NIGHTINGALE, K., DIMITROV, S., REEVES, R. and WOLFFE, A. (1996). Evidence for a shared structural role for HMG1 and linker histones $B 4$ and $\mathrm{H} 1$ in organizing chromatin. EMBO J 15: 548-561.

O'FARRELL, P.H., STUMPFF, J. and SU, T.T. (2004). Embryonic cleavage cycles: how is a mouse like a fly? Curr Biol 14: R35-R45.

ONIKUBO, T., NICKLAY, J.J., XING, L., WARREN, C., ANSON, B., WANG, W.L., BURGOS, E.S., RUFF, S.E., SHABANOWITZ, J., CHENG, R.H. et al., (2015), Developmentally Regulated Post-translational Modification of Nucleoplasmin Controls Histone Sequestration and Deposition. Cell Rep. 10: 1735-1748.

PHILPOTT, A., LENO, G. and LASKEY, R. (1991). Sperm decondensation in Xenopus egg cytoplasm is mediated by nucleoplasmin. Cell 65: 569-578.

PRIOLEAU, M.N., BUCKLE, R.S. and MECHALI, M. (1995). Programming of a repressed but committed chromatin structure during early development. $E M B O$ J 14: 5073-5084.

PRIOLEAU, M.N., HUET, J., SENTENAC, A. and MECHALI, M. (1994). Competition between chromatin and transcription complex assembly regulates gene expression during early development. Cell 77: 439-449.

QUIVY, J.P., GRANDI, P. and ALMOUZNI, G. (2001). Dimerization of the largest subunit of chromatin assembly factor 1 : importance in vitro and during Xenopus early development. EMBO J 20: 2015-2027.

RAMACHANDRAN, S. and HENIKOFF, S. (2015). Replicating nucleosomes. SCi Adv 1:e1500587 7.

RAY-GALLET, D., QUIVY, J.P., SCAMPS, C., MARTINI, E.M., LIPINSKI, M. and ALMOUZNI, G. (2002). HIRA is critical for a nucleosome assembly pathway independent of DNA synthesis. Mol Cell 9: 1091-1100.

RAY-GALLET, D., QUIVY, J.P., SILLJE, H.W., NIGG, E.A. and ALMOUZNI, G. (2007). The histone chaperone Asf1 is dispensable for direct de novo histone deposition in Xenopus egg extracts. Chromosoma 116: 487-496.

SCHIER, A.F. (2007). The maternal-zygotic transition: death and birth of RNAs. Science 316: 406-407.

SERA, T. and WOLFFE, A.P. (1998). Role of histone $\mathrm{H} 1$ as an architectural determinant of chromatin structure and as a specific repressor of transcription on Xenopus oocyte 5S rRNA genes. Mol Cell Biol 18: 3668-3680.
SHECHTER, D. and ALLIS, C.D. (2007). Alasting marriage: histones and DNA tie a knot that is here to stay. Nature Reviews Genetics DNA Technologies Supplement: S23.

SHECHTER, D., CHITTA, R.K., XIAO, A., SHABANOWITZ, J., HUNT, D.F. and ALLIS, C.D. (2009a). A distinct H2A.X isoform is enriched in Xenopus laevis eggs and early embryos and is phosphorylated in the absence of a checkpoint. Proc Natl Acad Sci USA 106: 749-754.

SHECHTER, D., NICKLAY, J.J., CHITTA, R.K., SHABANOWITZ, J., HUNT, D.F. and ALLIS, C.D. (2009b). Analysis of histones in Xenopus laevis. I. A distinct index of enriched variants and modifications exists in each cell type and is remodeled during developmental transitions. J Biol Chem 284: 1064-1074.

SHINTOMI, K., TAKAHASHI, T.S. and HIRANO, T. (2015). Reconstitution of mitotic chromatids with a minimum set of purified factors. Nat Cell Biol 17: 1014-1023.

SIMEONI, I., GILCHRIST, M.J., GARRETT, N., ARMISEN, J. and GURDON, J.B. (2011). Widespread Transcription in an Amphibian Oocyte Relates to Its Reprogramming Activity on Transplanted Somatic Nuclei. Stem Cells Dev. 21: 181-190.

STEINBACH, O.C., WOLFFE, A.P. and RUPP, R.A. (1997). Somatic linker histones cause loss of mesodermal competence in Xenopus. Nature 389: 395-399.

STRAHL, B.D. and ALLIS, C.D. (2000). The language of covalent histone modifications. Nature 403: 41-45.

SZENKER, E., LACOSTE, N. and ALMOUZNI, G. (2012). A Developmental Requirement for HIRA-Dependent H3.3 Deposition Revealed at Gastrulation in Xenopus. Cell Reports 1: 730-740.

TADROS, W. and LIPSHITZ, H.D. (2009). The maternal-to-zygotic transition: a play in two acts. Development 136: 3033-3042.

TOYODA, T. and WOLFFE, A.P. (1992). In vitro transcription by RNA polymerase II in extracts of Xenopus oocytes, eggs, and somatic cells. Anal Biochem 203:340-347.

TUTTER, A.V. and WALTER, J.C. (2006). Chromosomal DNA replication in a soluble cell-free system derived from Xenopus eggs. Methods Mol Biol 322: 121-137.

VAN HOLDE, K.E. (1989). Chromatin. Springer-Verlag, New York.

VENKATESH, S. and WORKMAN, J.L. (2015). Histone exchange, chromatin structure and the regulation of transcription. Nat Rev Mol Cell Biol 16: 178-189.

WANG, W.-L., ANDERSON, L., NICKLAY, J., CHEN, H., GAMBLE, M., SHABANOWITZ, J., HUNT, D. and SHECHTER, D. (2014). Phosphorylation and arginine methylation mark histone $\mathrm{H} 2 \mathrm{~A}$ prior to deposition during Xenopus laevis development. Epigen. Chromatin 7: 22

WANG, W.-L. and SHECHTER, D. (2016). Chromatin assembly and transcriptional cross-talk in Xenopus laevis oocyte and egg extracts. Int. J. Dev. Biol. 60:315-320.

WILCZEK, C., SHECHTER, D., CHITTA, R., SHABANOWITZ, J., HUNT, D.F., WOO, E. and CHAIT, B.T. (2011). Protein arginine methyltransferase Prmt5-Mep50 methylates histones $\mathrm{H} 2 \mathrm{~A}$ and $\mathrm{H} 4$ and the histone chaperone nucleoplasmin in Xenopus laevis eggs. J. Biol. Chem. 286: 42221-42231.

WOLFFE, A., ALMOUZNI, G., URA, K., PRUSS, D. and HAYES, J. (1993). Transcription factor access to DNA in the nucleosome. Cold Spring Harb Symp Quant Biol 58: 225-235.

WOODCOCK, C.L., SKOULTCHI, A.I. and FAN, Y. (2006). Role of linker histone in chromatin structure and function: $\mathrm{H} 1$ stoichiometry and nucleosome repeat length. Chromosome Res 14: 17-25.

WOODLAND, H. (1979). The modification of stored histones $\mathrm{H} 3$ and $\mathrm{H} 4$ during the oogenesis and early development of Xenopus laevis. Dev Biol 68: 360-370.

WOODLAND, H. and ADAMSON, E. (1977). The synthesis and storage of histones during the oogenesis of Xenopus laevis. Dev Biol 57: 118-135. 


\section{Further Related Reading, published previously in the Int. J. Dev. Biol.}

Control of timing of embryonic M-phase entry and exit is differentially sensitive to CDK1 and PP2A balance Mohammed El Dika, Damian Dudka, Claude Prigent, Jean-Pierre Tassan, Malgorzata Kloc and Jacek Z. Kubiak Int. J. Dev. Biol. (2014) 58: 767-774

Identification of the sperm motility-initiating substance in the newt, Cynops pyrrhogaster, and its possible relationship with the acrosome reaction during internal fertilization

Toshihiko Watanabe, Hideo Kubo, Shinya Takeshima, Mami Nakagawa, Manami Ohta, Saori Kamimura, Eriko Takayama-Watanabe, Akihiko Watanabe, and Kazuo Onitake

Int. J. Dev. Biol. (2010) 54: 591-597

Signalling molecules involved in mouse bladder smooth muscle cellular differentiation

Benchun Liu, Dongxiao Feng, Guiting Lin, Mei Cao, Yuet Wai Kan, Gerald R. Cunha and Laurence S. Baskin

Int. J. Dev. Biol. (2010) 54: 175-180

Nuclear reprogramming in zygotes

Chanchao Lorthongpanich, Davor Solter and Chin Yan Lim

Int. J. Dev. Biol. (2010) 54: 1631-1640

Faithful reprogramming to pluripotency in mammals - what does nuclear transfer teach us? Julien Maruotti, Alice Jouneau and Jean-Paul Renard

Int. J. Dev. Biol. (2010) 54: 1609-1621

Gonad-stimulating substance-like molecule from the radial nerve of the sea cucumber Hideki Katow, Tomoko Katow and Akihiko Moriyama

Int. J. Dev. Biol. (2009) 53: 483-491

Cyclin B2/cyclin-dependent kinase1 dissociation precedes CDK1 Thr-161 dephosphorylation upon M-phase promoting factor inactivation in Xenopus laevis cell-free extract

Franck Chesnel, Franck Bazile, Aude Pascal and Jacek Z. Kubiak

Int. J. Dev. Biol. (2007) 51: 297-305

Remodeling of sperm chromatin induced in egg extracts of amphibians.

C Katagiri and K Ohsumi

Int. J. Dev. Biol. (1994) 38: 209-216

The influence of mouse sera, regenerating liver extracts and bacterial products on the abilities of different cells in vitro.

N Zarkovic, M Osmak, D Novak, N Lers and M Jurin

Int. J. Dev. Biol. (1991) 35: 239-249

Hormonal factors from the mammalian pineal gland interfere with cell development in Hydra.

W A Müller, C Bartsch, H Bartsch, I Maidonis and E Bayer

Int. J. Dev. Biol. (1998) 42: 821-824
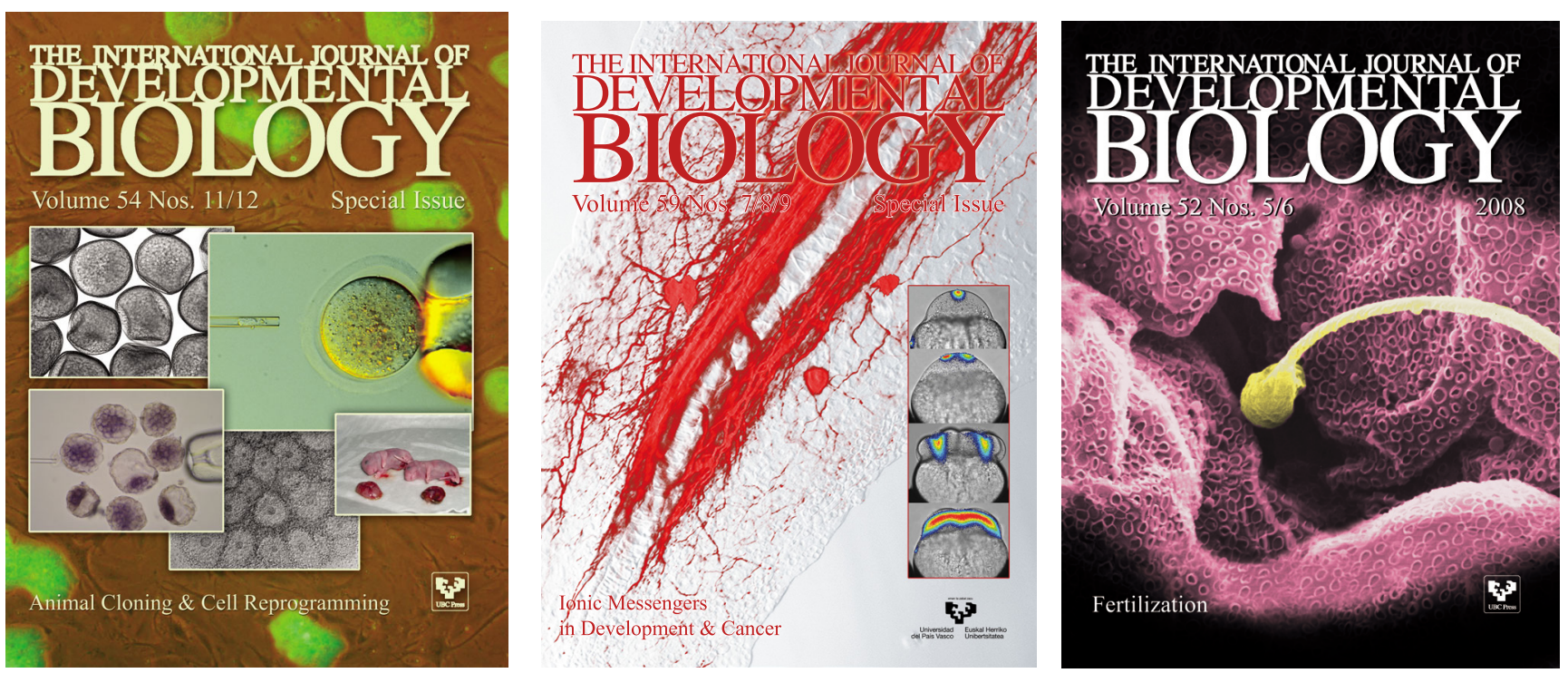